\title{
High-energy seismic events in Legnica-Głogów Copper District in light of ASG-EUPOS data
}

\author{
Zbigniew Szczerbowski ${ }^{1 *}$
}

\author{
${ }^{1}$ Faculty of Mining Surveying and Environmental Engineering, Department of Mining Areas Protection, \\ Geoinformatics and Mining Surveying, AGH University of Science and Technology, al. A. Mickiewicza 30, \\ 30-059 Cracow, Poland \\ *szczerbo@agh.edu.pl
}

\begin{abstract}
Seismic events in the area of Poland are related mostly to copper and coal mining, and they are regarded as the most dangerous natural hazard. Although development of geomechanical modelling as the development of geophysical methods determining seismic hazard are evident, low predictability of the time-effect relationship still remains. Geomechanical models as geophysical data analysis highlight the interaction between parts of rock mass or allow to reconstruct the way of rock mass destruction and to understand the processes that take place in the high-energy tremors.

However, the association of larger mining tremors with pre-existing geological features has been reported by many investigators; in geomechanical practice, investigations of rock mass condition concentrate on this problem in the local scale. Therefore, the problem of relations between high-energy seismic events in Legnica-Głogów Copper District (LGCD) and regional scale deformations of terrain surface resulting from possible tectonic activity is discussed in this paper. The GNSS data evaluated from the observations of ASG-EUPOS (Active Geodetic Network - EUPOS) stations in the area of LGCD and in the adjacent areas is analysed in this study. Temporal variation of distances between the stations and evaluated on that base so called apparent strain was combined with the occurrence of high-energy tremors. Consequently, after the examination and analysis of occurrences of mining tremors, it is found that high-energy seismic events and periods of strain accumulation evaluated from GPS/GNSS data have temporal relations. Although the seismic events were triggered by mining, nearly all the events with energy $E>10^{8} \mathrm{~J}$ occurred in the periods when the analysed stations' positions demonstrated a decrease in the baseline length.
\end{abstract}

Key words: neotectonics, permanent GPS/GNSS observations, horizontal displacements mining tremors

\section{Introduction}

Natural state of stress in a rock mass depends on many factors as gravity, tectonics, and so on. But this state disturbed by mining leads to local increases or decreases of stress. Geomechanical condition is fundamental in the process of deformation and changes in stress field. Seismicity induced by mining and earthquakes have the same basic mechanisms but they occur on different scales. The similarity in both is the difficulty in prediction. A large amount of work has been spent on solving the problem of modelling of stress in rock mass as predicting earthquakes or mining rockburst. Probably most of them were devoted to California, where geodynamical monitoring in large scale is applied due to earthquake hazard there. The fundamental is the measurements of deformation resulting from the constant motion of the Pacific and North American tectonic plates in the western United States. As displacements are permanent and can be determined at some distance away from large earthquakes by geodetic measurements such as classic or GPS measurements (Wdowinski et al., 1997).

Due to the monitoring carried out, earthquake hazards in the area of San Andreas Fault System are assessed from fault slip rate estimates. However, the estimates of slip measured by the long-term offset of physical geologic features do not always 
match modern estimates from precise positioning GPS measurements, model simulating interseismic strain accumulation, historical earthquake ruptures, and postseismic stress relaxation over several hundred years and slip rates evaluated from geological data and GPS rate measurements can improve the understanding of earthquake mechanisms and reduce risk (McCaffrey, 2005; Lohman and McGuire, 2007; Tong et al., 2014).

However, the geodetic measurements yield strain data evaluated from displacements measured usually by GNSS technique, anticipation of reliable studies on natural earthquakes and particularly on the precursors of earthquakes lies in the joint geophysical and geodetic research. Hence, a number of papers on geodetic surveys in earthquake studies show an important role of geodesy in earthquake physics. Geodetic studies provide such significant benefits as monitoring the effects of earthquakes, including post-seismic relaxation, estimating the structural deformations of large engineering structures, compiling a variety of satellite data that can be used by civil engineers (Feigl, 2002; Crowell et al., 2012; Melgar et al., 2012).

Although, when a rock mass is penetrated by mining, its geomechanical properties and stress field change under the influence of excavation works. The geological setting (rock types, their bedding, faults) plays a crucial role in the mechanism of mining tremors and the relaxation of the stress field in a rock mass. But in the Polish mining, there are many unexpected seismic events as in the areas of multi-seam exploitation, where seismic phenomena seem likely to occur even in the situation of the lack of strata capable of accumulating elastic energy and its dynamic release (Majcherczyk and Niedbalski, 2017).

While geodetic surveys play an important role in many scientific programs, observatories, networks or test fields involved in an integrated system of interdisciplinary observations, providing fundamentally important datasets in earthquake studies, as far their insufficient role in country studies on mining induced seismicity is harmful, it is amazing. Thus, so far, the research achievements in combining geophysical and geodetic aspects for modelling of a rock mass deformation induced by mining tremors as rockbursts or releasing seismic energy remain insufficient.

So, this study shows a certain approach in GNSS data analysis for the determination of stress field that is varying in the area of LGCD to find some relations with seismic events. However, they are induced by mining but many of them are conditioned by regional tectonic stress. In this study, observed variation of positions of GNSS is the motivated subject for combining the results of determined displacements and strains with high energy events occurred in the area. Strain analysis is typically based on GPS/GNSS as velocity, that is, displacement rates determined for a time interval. This study presents an analysis based on day by day observations between 2008-2014 to depict the significance of periodic variations of stations' coordinates and the occurrence of tremors releasing high energy as a probable consequence of the natural stress variation. The evaluations from varying coordinates baseline lengths are influenced by several sources that couldn't be identified precisely (GPS technique itself, effect of atmosphere, hydrology, equipment, variable environmental influences in the year). So, in consequence, the displacement evaluated on the basis of these varying coordinates in relation to the reference length is a measure that should be regarded as apparent strain. And this term can be described by operational definition as strain calculated from data affected by errors hard to be estimated.

\section{Seismic and aseismic deformations inter- play}

High seismic activity in the Polish copper mine areas is the most significant danger with high energy tremors that can be considered as small earthquakes in tectonic active areas. Rockbursts are just caused by high-energy tremors induced by mining works. Mining-induced stress changes by excavation works are always associated with displacements of rock mass, which may lead blocks of rock mass to slip along the pre-existing zones of discontinuities or fracturing. Natural earthquakes resulting from tectonic movements are usually presumed as an ongoing process with which the stress concentration accommodates although its activity can vary in time. Wide range of surveys carried out in the areas of active faults suggests that the aseismic motion occurs on the same fault plane as seismic events (Lohman and McGuire, 2007). However, the deformation signals observed at the surface by GNSS provide only terrestrial and macroscopic view of the process at depth and the details related to the movements are often lacking due to the limited resolution resulted from the distribution of the GNSS stations (Lengliné et al., 2012).

Long-time experience in deformation measurements in Polish mining provided some interesting results on the problem of tremors and rockburst, but few studies deal with the problem in the context of deformations detected by geodetic surveys. Such a study was carried out by Wanior (1983) who stated that the phenomena is in many cases preceded by abnormal displacements determined in underground surveys. Their values were differing from those that form subsidence basins caused by extracted strata. The values of uplifts for preceding mining tremors and detected by spirit levelling in underground were proportional to the energy of the tremors or rockbursts, which occurred afterwards. Idea of the study by Wanior was continued by Szczerbowski and Jura, who analysed the high energy seismic events in the Polish copper mines (Szczerbowski and Jura, 2015). Their analysis on GNSS times series provided some relations between the amplitude of vertical displacements observed in the GNSS stations and the distance from the epicentre of the analysed tremors. Similar conclusions were derived in another Polish mining district: Upper Silesia Coal Basin. During longwall exploitation in the Coal-Mine "Pokój" temporal distribution of vertical displacements determined for GNSS stations in the area demonstrated relations with occurrences of tremors. Some distinguishing changes in the subsidence velocity or uplift as the next increase of subsidence velocity were considered as a disturbance in the course of vertical displacements (Sokoła-Szewioła, 2011). This disturbance occurred before each of the analysed tremors and according to SokołaSzewioła, it can be considered as a predictor of tremor induced by longwall mining.

Thus, so far there are no significant studies, which combine geophysical and geodetic research in the modelling of the deformation of a rock mass induced by mining tremors in the conditions of the Polish mining areas. The few geodetic studies (Wanior, 1983; Popiołek et al., 2001; Szczerbowski and Jura, 2015), which are devoted to this topic, are unfortunately based on insufficient geodetic data (the number of points, spatial distribution, frequency of measurements, etc.). So, they can be considered only as initial but promising studies on the still open problem precursors of mining tremors, which is wide research area to be explored. 


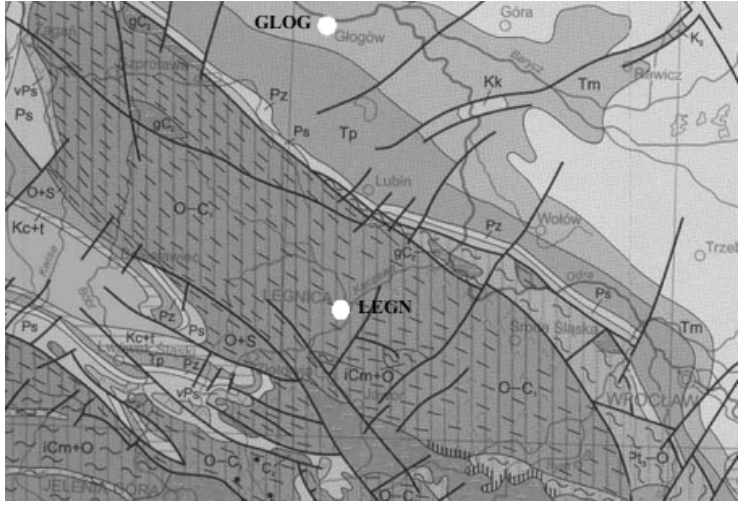

Figure 1. Geological map of the study (according to Dadlez et al. (2000)) and location of the LEGN and GLOG stations

\section{Geological setting and recent tectonic activ- ity}

Multidisciplinary subject of the work involves geological, especially tectonic data, background of seismic phenomenon of the area and geodetic data that are especially applied in the presented analysis. In many cases, understanding the geodetic data requires examination of geological context. So, the main geological feature of LGCD area is monocline structure with intensive faulting.

It is clear that geological background (tectonic setting, mechanical properties of rocks) as mining operation techniques are fundamental in the study of mining seismicity. Area of LGCD is strongly disturbed tectonically with numerous faults and high-energy tremors and rockburst hazard as a result of mining operations and mechanical properties of rock mass.

The discussed area of LGCD is situated in the southern marginal zone of the Fore-Sudetic Monocline. Three main tectonic units have been distinguished in the area: a metamorphosed Proterozoic-Palaeozoic basement, a Permo-Triassic complex of sedimentary rocks, which is smoothly dipping to the northeast and thick, nearly horizontal lying Cenozoic sediments above.

Although the stratigraphy sketch is quite simple as compared with the neighbouring Fore-Sudetic Block, but geology of the area has a distinct expression in the pattern of fault system. The main faults are presented on Fig. 1. However, copper belt area is a part of the monocline, two main cities of the district: Legnica and Głogów are located on different geological units, accordingly the Fore-Sudetic Block and the Fore-Sudetic Monocline. They are separated by the Middle Odra Northern Fault.

Presumed tectonic stress and possible tectonic activity of the area can be interpreted as regional effect and response to such an activity of the Sudetes. Effect of tectonic processes/phenomena can be revealed by the so-called tectonic events by instruments working permanently with micro or nano-meter accuracy. Temporal variations of data provided by instruments working permanently with micro or nano-meter accuracy in Geodynamic Laboratory in Książ are interpreted as the result of tectonic tilting of rock blocks (Kaczorowski and Wojewoda, 2011). The observations are carried by water tube tiltmeter, and extensometers demonstrated some regularities in deformation parameters in certain periods as a result of tension caused by tectonic stress that is considered as recent tectonic activity of the Sudetes. Many tectonic events in the area of the Sudetes were discussed among others in the studies of Kaczorowski and Wojewoda (2011) and Brzeziński et al. (2016).

Similar studies on recent geodynamic activity within the Sudeten and fault zones of the Bohemian Massif (Central
Europe) were carried out with the use of crack gauges and tiltmeters located on specific geological structures within caves and galleries. The recorded data with the support of rangefinder, seismic and groundwater observations showed some significant pressure phenomenon considered as tectonic pressure pulse that were reported by many researchers (Košt'ák et al., 2011; Schenk et al., 2009; Stemberk et al., 2010).

Wide range of neotectonic investigations carried out in the Sudetes and adjacent areas, mostly at the known fault zones by various types of geodetic measurements provided results that were discussed in the previous studies (Cacon et al., 2004; Kontny, 2004).

The area lies in a zone of subsidence extending from the North Sea to the north-western part of the Carpathian arc, and its recent activity was documented by precise levelling (Grzempowski et al., 2009, 2012). Although the levelling measurements provided distinct regional movements, horizontal displacement results of repeated GPS measurements as strain distribution calculated on the basis of velocities of GPS points are incoherent (Cacon et al., 2004; Jarosiński, 2010; Grzempowski et al., 2012). Local surveys were more optimistic: Kontny (2004) reported present-day activity of the Sudetic Marginal Fault, based on the results of GPS measurements carried out between 1996 and 2002 deduced that the main fault zone had undergone to NE-SW compression.

This supposed stress corresponds to the results of borehole breakout analysis performed within the adjacent areas discussed in the paper: present-day maximum horizontal stress within Fore-Sudetic Monocline SSW-NNE (Jarosiński, 2010) as well as with the GPS measurements (maximum compression within Sudeten and the Fore-Sudetic Block SW-NE (Kontny, 2004).

The seismic events in LGCD are conditioned by mining operations as geomechanical properties of rocks. There are thick carbonate rock formation and strong, rigid anhydrite rocks with capability of elastic energy of accumulation. Investigations of seismicity in the LGCD area provided that normal dipslip mechanism was dominating in strong seismic events, and in many cases, noticeable horizontal movement at the events foci was found (Pilecka, 2007).

As it was considered before, the tectonic pattern, among just the mentioned lithological and geomechanical properties, is considered as a factor playing seismically important role in the area of LGCD. This subject was discussed among others by Orlecka-Sikora et al. (2009) and a statistical relationship between tectonic line positions and vectors of epicentres of tremors and high-energy induced seismic activity in the mines was reported by (Pilecka, 2008).

The moment tensor solutions for many tremors in the copper mine district shows that although no regularity was recognized in the pattern of focal mechanisms, it can be inferred that the strongest events of strike-slip focal mechanisms indicate maximum horizontal stress $\left(S_{\mathrm{H}_{\max }}\right)$ in the range between NNWSSE and NNE-SSW (Wiejacz and Gibowicz, 1997; Jarosiński, 2010).

Another subject of the problem is the influence of tremors on faults. Spatial-temporal patterns of seismic tremors in Legnica-Głogów Copper District suggests that mining excavation operations in the vicinity of faults of considerable throw cause faults activation, which often results in high-energy tremors and rockbursts. The problem of impact of fault disturbances on the possibility of tremors and rockburst is the essential issue. Some researchers reported the probable faults reactivation as the cause of seismic events (Zorychta and Bur$\tan , 2012$ ). Nonetheless, the reverse side of the problem of interactions between non-stationary mining induced stress field and natural stress field in intact rock mass field is that relationship in conditions of natural stress field variation related 
to fault interaction. In the scope this study, the problem is essential for understanding the observed strains as a result of tectonic stress.

Presented above is a short overview of the results of the research on the manifestations of tectonic activity in ForeSudetic Monocline and adjacent areas prove promising. In particular, the pattern of tectonic signals shows that it is not large and not constant. So, the results raise a question about whether mining induced seismic events with relatively large energies in the area of LGCD demonstrate response to a tectonic stress, such as compression as triggering the effect of regional stress redistribution caused by mining.

\section{The data}

As mentioned before, the observations suggested that the recent tectonic activity of the Sudetes and their Foreland occurs during particular intervals of time. Such performance requires permanent observations (GNSS, tiltmeters, tensiometers, etc.); so, the occasional survey campaigns fail to observe tectonic stress effects. So, the application of GNSS stations' velocities, particularly from periodic campaigns seems to be pointless if tectonic stress is non-stationary. On the other hand, the rigidblock tectonic model of the area comprising faults separating the major tectonic structures should reflect in the tectonic deformation field, presumably with a complex outline.

Considering block pattern in geological structure of the area and assuming tectonic activity of the area, Szczerbowski (2016) presented a certain approach to recognize tectonic effects in varying values of GPS/GNSS observations. Statistical analysis of variation of azimuths of displacement vectors that were derived from varying values of GPS/GNSS permanent observations, some frequent directions were distinguished without seasonal effects. In many stations, the analysed directions of detrended displacement vectors correspond to the orientation of tectonic lines. So, the statistical distribution of daily solutions of GNSS stations located in the Sudetes and adjacent areas including the analysed further on stations in the area of LGCD are not random, and in most stations, are oriented accordingly towards the Sudetes. It was concluded that the directions of temporal stations' position changes can be an indication of the impulse tectonic movements and their repeatability can be assumed as an attribute depicting a response of tectonic stress release in the form of displacements Szczerbowski (2016).

This study is a next stage of the research, where temporal relations between positions of permanent stations of ASGEUPOS network are analysed. It was presumed that the observed variations of the positions are resulted from the movement of geological basement due to a fault system in the area. The presented investigation deal with problem of strain based on horizontal displacements of GNSS stations in the area of Legnica-Głogów Copper District and adjacent areas. The analysis comprised daily displacements evaluated from the changes of the stations' position. Analysed stations were CPAR, CTRU, WLBR, LEGN, GLOG and LESZ.

The day by day positions were applied for determinations of changes of the distance between pairs of the stations. The changes were calculated as the next as variation of defined before apparent strain in reference to the initial measurements carried out on $1^{\text {st }}$ June 2008 .

Since $1^{\text {st }}$ June 2008, when the ASG-EUPOS (Active Geodetic Network), a country system for precise satellite positioning in Poland started to operate with full operability (Bosy et al., 2007), many studies have been conducted to explore tectonic movements. So, the studies in geodynamics utilizing the system has been applied and a great number of papers were devoted to regional and also to local aspects of geodynamics (Bo- gusz et al., 2012; Kontny and Bogusz, 2012; Bogusz et al., 2014; Klos et al., 2015; Araszkiewicz et al., 2016). In a common approach, the velocities of the network's stations derived on daily outcomes (so-called daily solutions) were analysed.

Presented reasoning and estimations are based on changes of $X, Y$ coordinates retrieved form ASG-EUPOS system as daily solutions (outcomes) and apparent strain meant as change in distance per unit of the original distance between pairs of the stations that was resulted from changes in their positions (coordinates), which were affected by several sources (atmosphere, hydrology, etc.).

According to the system's general standards, the accuracy of daily horizontal results is about $2 \mathrm{~mm}$ for each coordinate (Araszkiewicz et al., 2009; Figurski et al., 2010). However, this value is in fact uncertainly estimated in mean and can be stated more precisely for data from individual station.

So, the changes of distances are considered and the reasoning encompass values transformed to local coordinate system. However, the first view of the distribution of horizontal coordinates values usually show significant outliers often exceeding the error bands and the temporal changes seems to be random.

As coordinates $(X, Y, Z)$ expressed in ETRF2000 were transformed from this geocentric to topocentric frame, all the components (North, East and Up) of displacement vectors were studied for initial detection of any non-random effects in their properties.

Estimated values of daily outcomes (solutions) were influenced by many errors and the precision of the data is changing in time. However, the derived daily displacements of the station are within range of the error; their distribution was not normal and some tendencies were evaluated Szczerbowski (2016).

To make reasoning more valid and understandable, the temporal distribution of N, E components of GLOG and LEGN stations are presented on Fig. 2 and Fig. 3. However, some oscillations are noticeable, no regularity is apparent and disturbances seem to play the main role in the distributions.

It can be concluded that the statistical properties of distribution of distances between pairs of the stations (vector magnitudes) as a variable depended on varying position of the stations (their temporal displacements) and should reflect the characteristics of the displacements' variability, as discussed by Szczerbowski (2016). So, the positions a displacement vector and linear deformation (apparent strain) are also changing in time. Apparent strain (extension or compression) is considered here as another quantity that is useful for more comparable analysis of performance of stations' position changes to distinct presumed tectonic effects. It was calculated day by day for the pairs of the stations making bases as, for example, LEGNGLOG. Distances for particular days were calculated with regard to up to date positions of the stations and evaluated apparent strain is just a ratio of distance changes to the initial dimension of the base. Presented on Fig. 4-Fig. 8, apparent strain variation in time evaluated for the analysed stations demonstrated much better consistency than changing in time the $\mathrm{N}$, E components of the stations. However, N, E values as their distribution in time are conditioned by applied reference frame or atmospheric effects, evaluated apparent strain reflects much better inter-dependency of the stations' positions and applied reference frame is unimportant. The most distinctive is temporal apparent strain distribution of the LEGN-GLOG base. No seasonality with cyclical pattern can be noticed in a strict sense for this performance. In the other cases, stress variations are minimal, so temporal distribution of apparent strain resulting from changing position of the LEGN and GLOG stations is surprising (Fig. 4). However, a pattern with interlaced maxima and minima can be distinguished, no regular cyclical fluctuations can be evaluated. So, a statistical analysis was carried out 


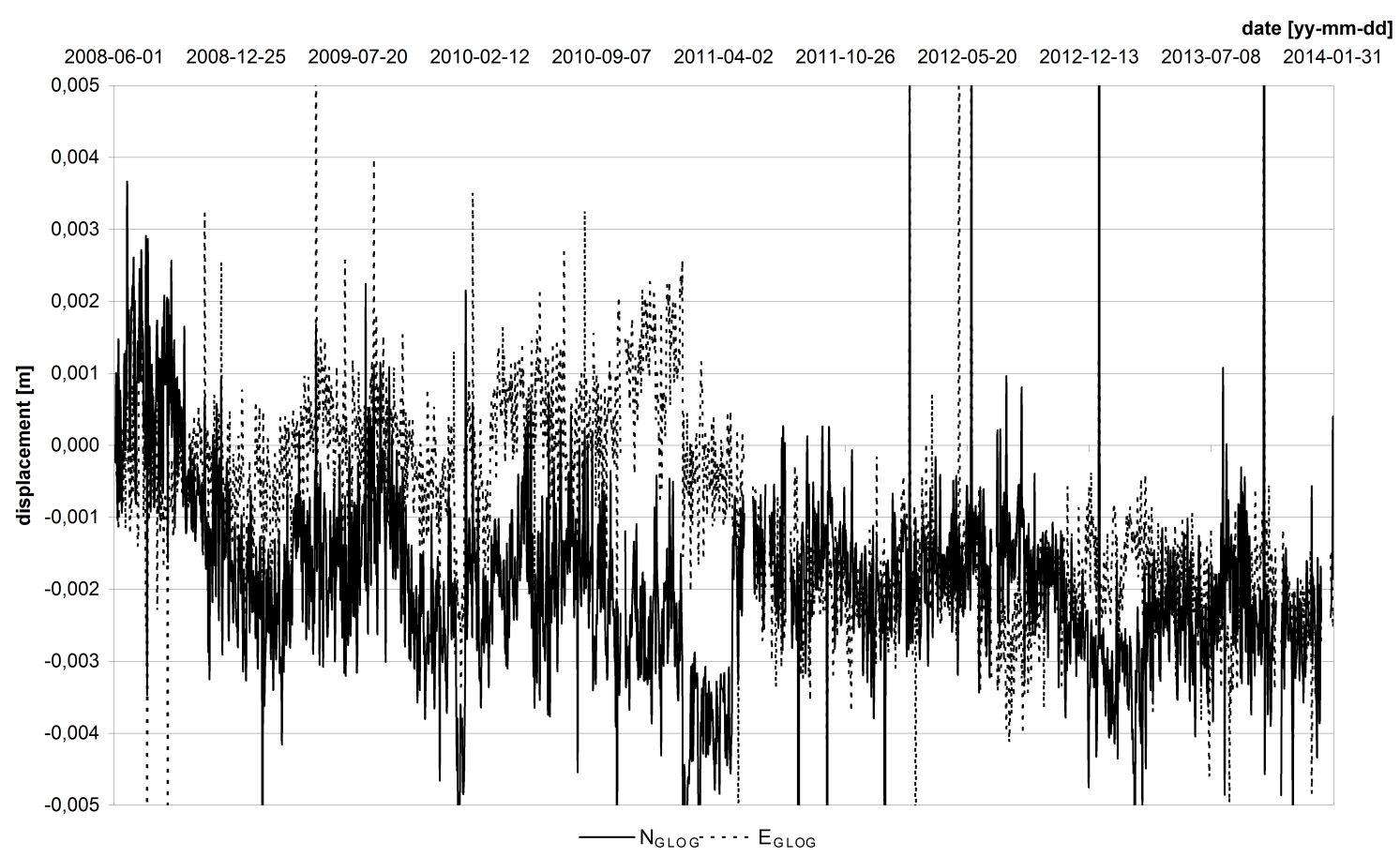

Figure 2. Temporal distribution of $\mathrm{N}$ and $\mathrm{E}$ components evaluated in the GLOG station

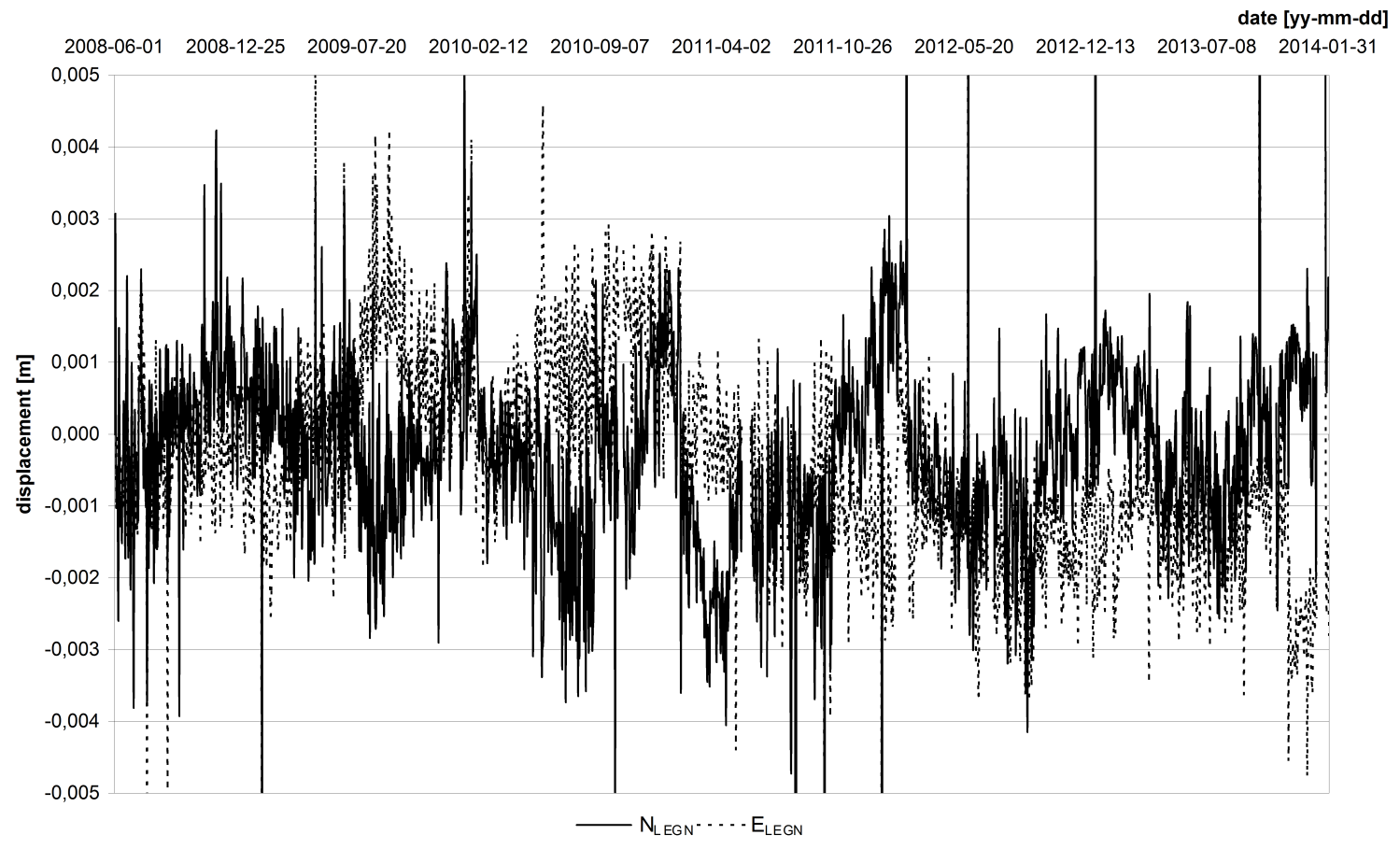

Figure 3. Temporal distribution of $\mathrm{N}$ and $\mathrm{E}$ components evaluated in the LEGN station 


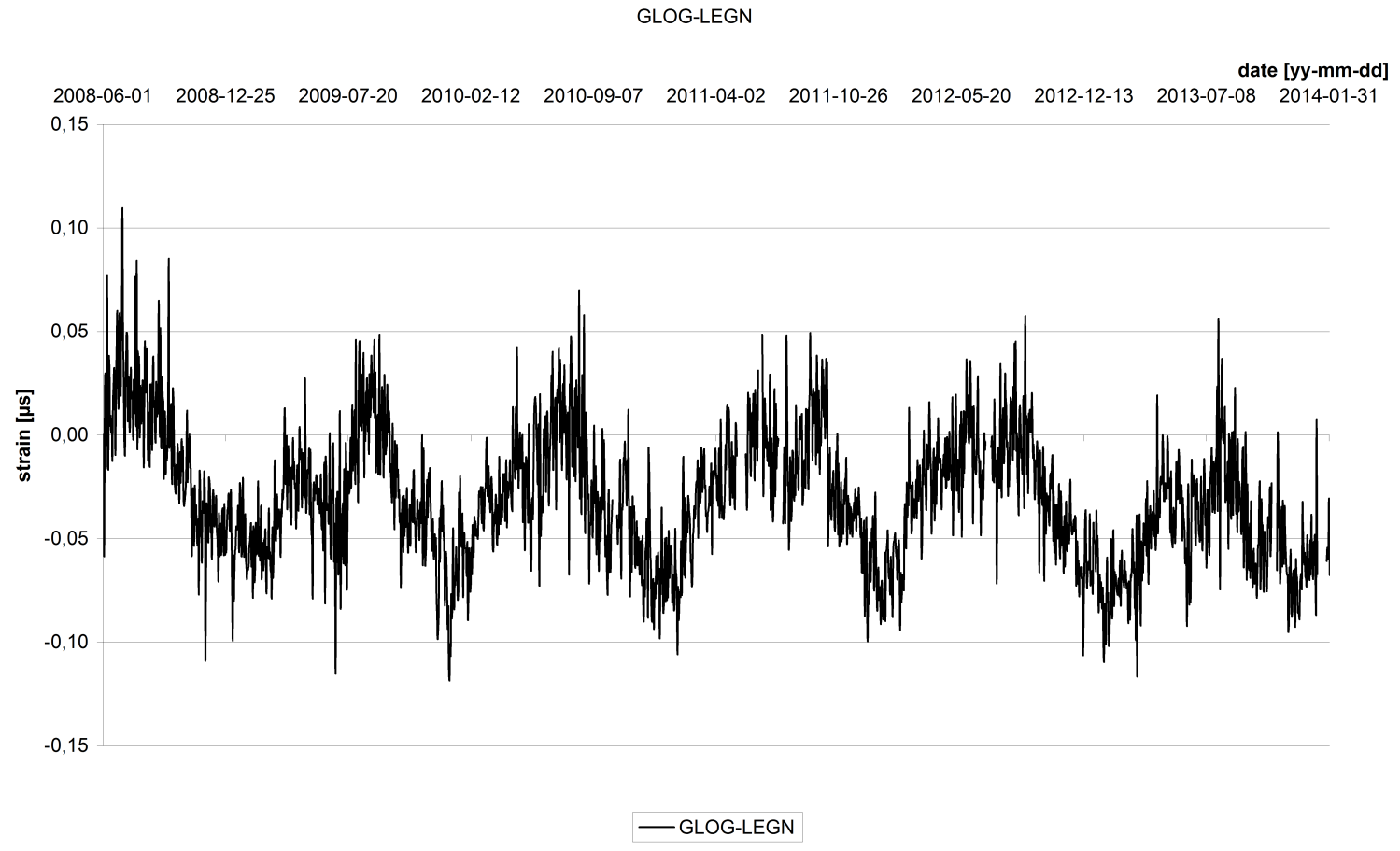

Figure 4. Temporal variation of apparent strain evaluated for the base LEGN-GLOG

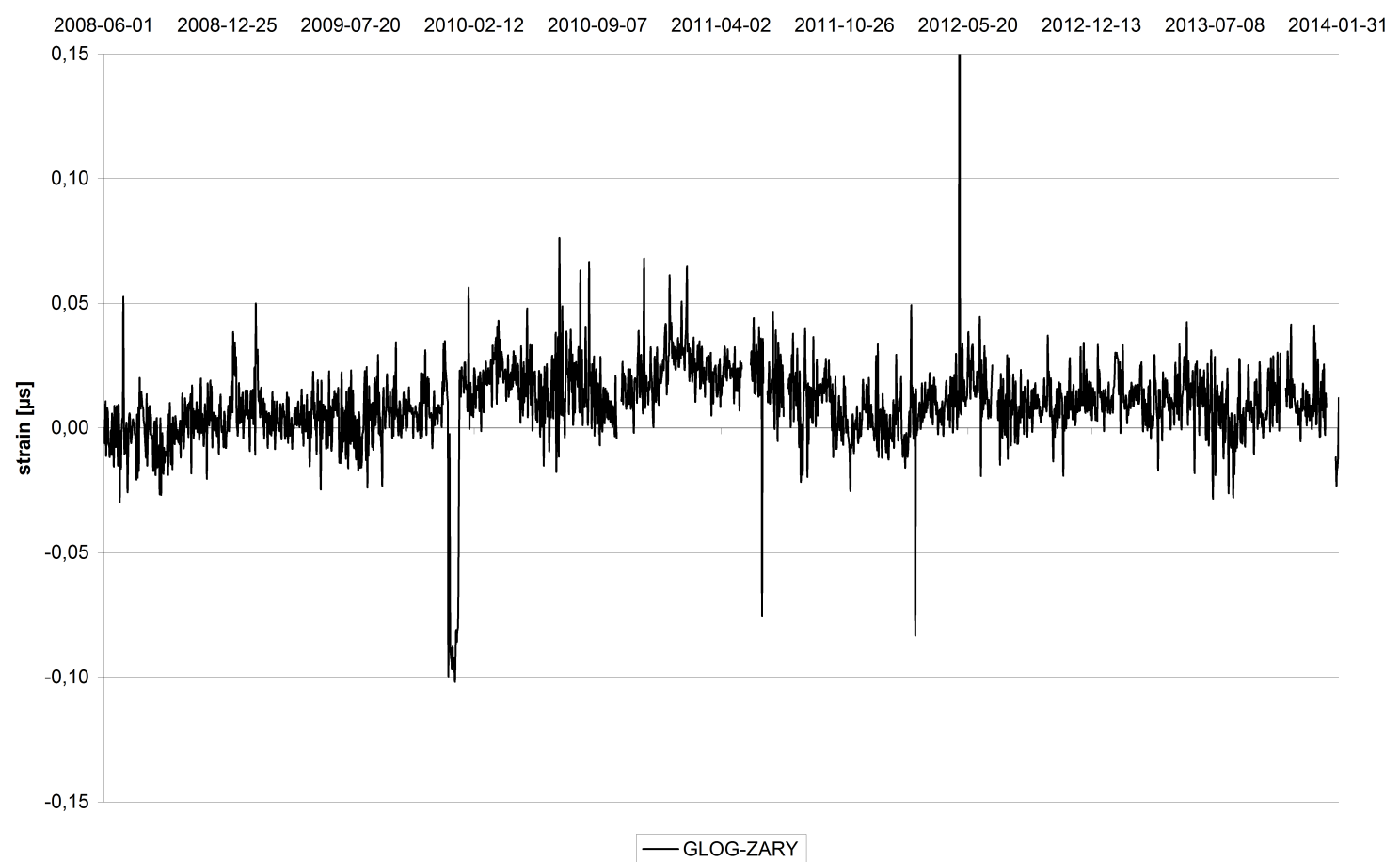

Figure 5. Temporal variation of apparent strain evaluated for the base GLOG-ZARY 


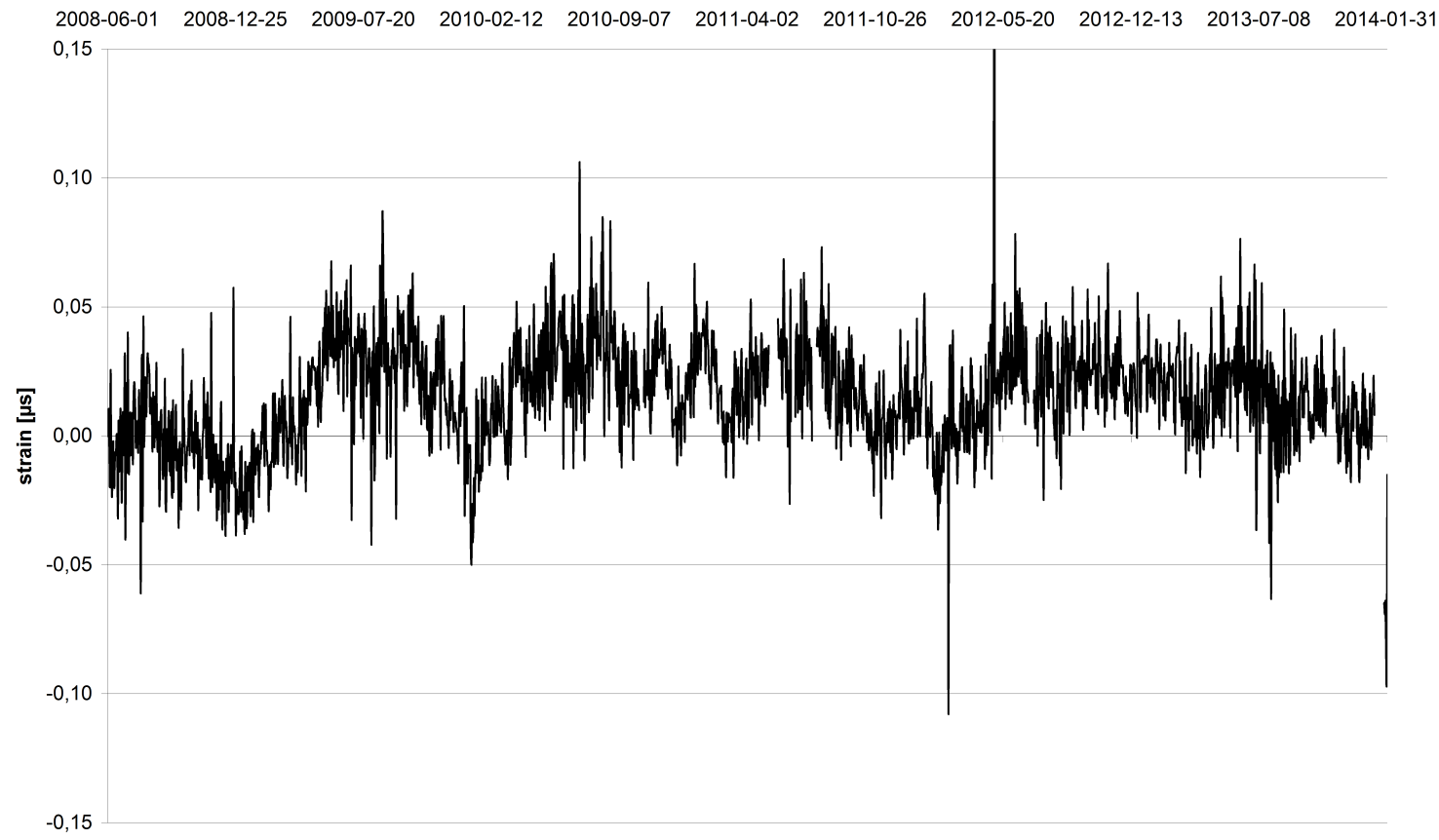

—GLOG-LESZ

Figure 6. Temporal variation of apparent strain evaluated for the base GLOG-LESZ

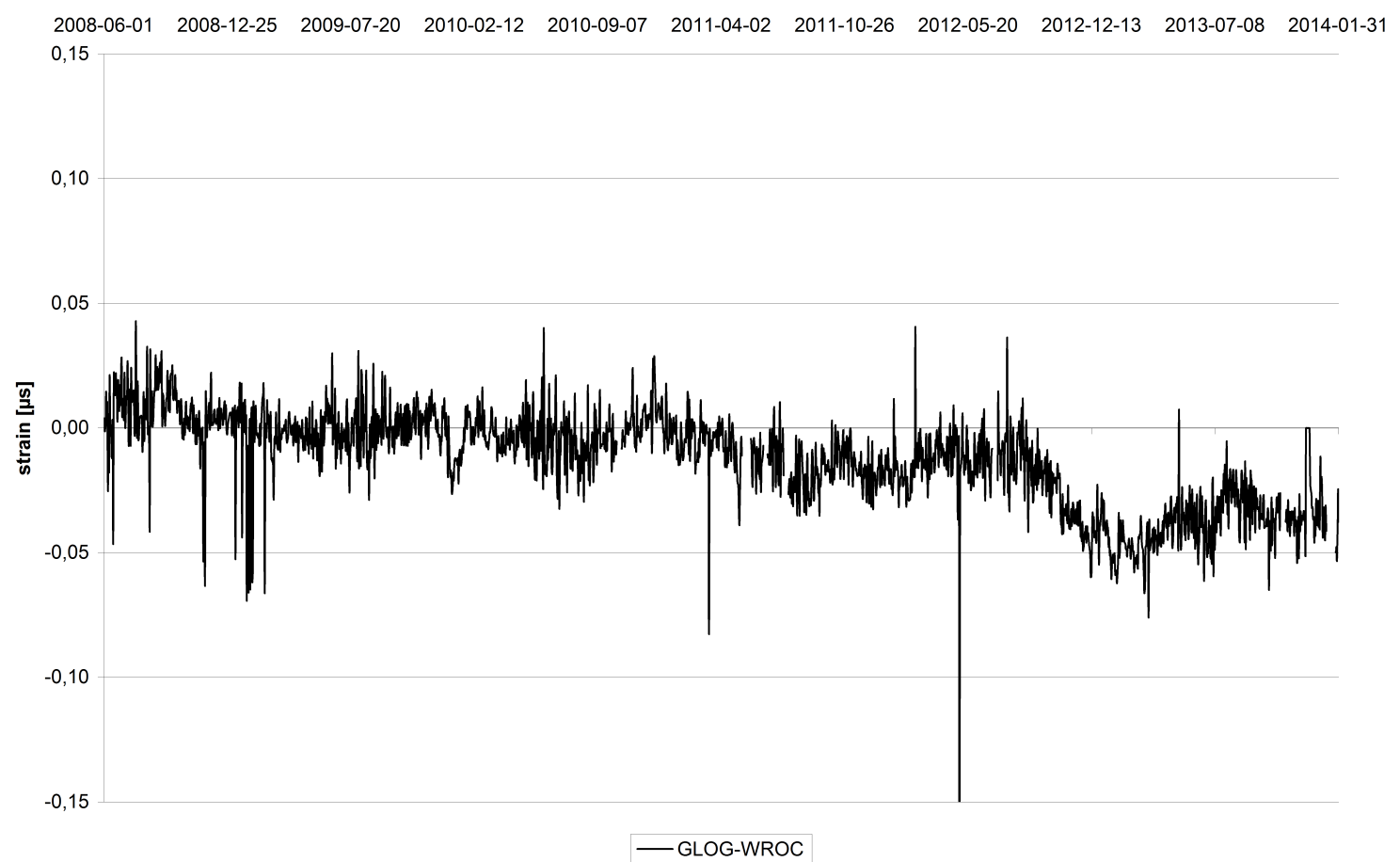

Figure 7. Temporal variation of apparent strain evaluated for the base GLOG-WROC 


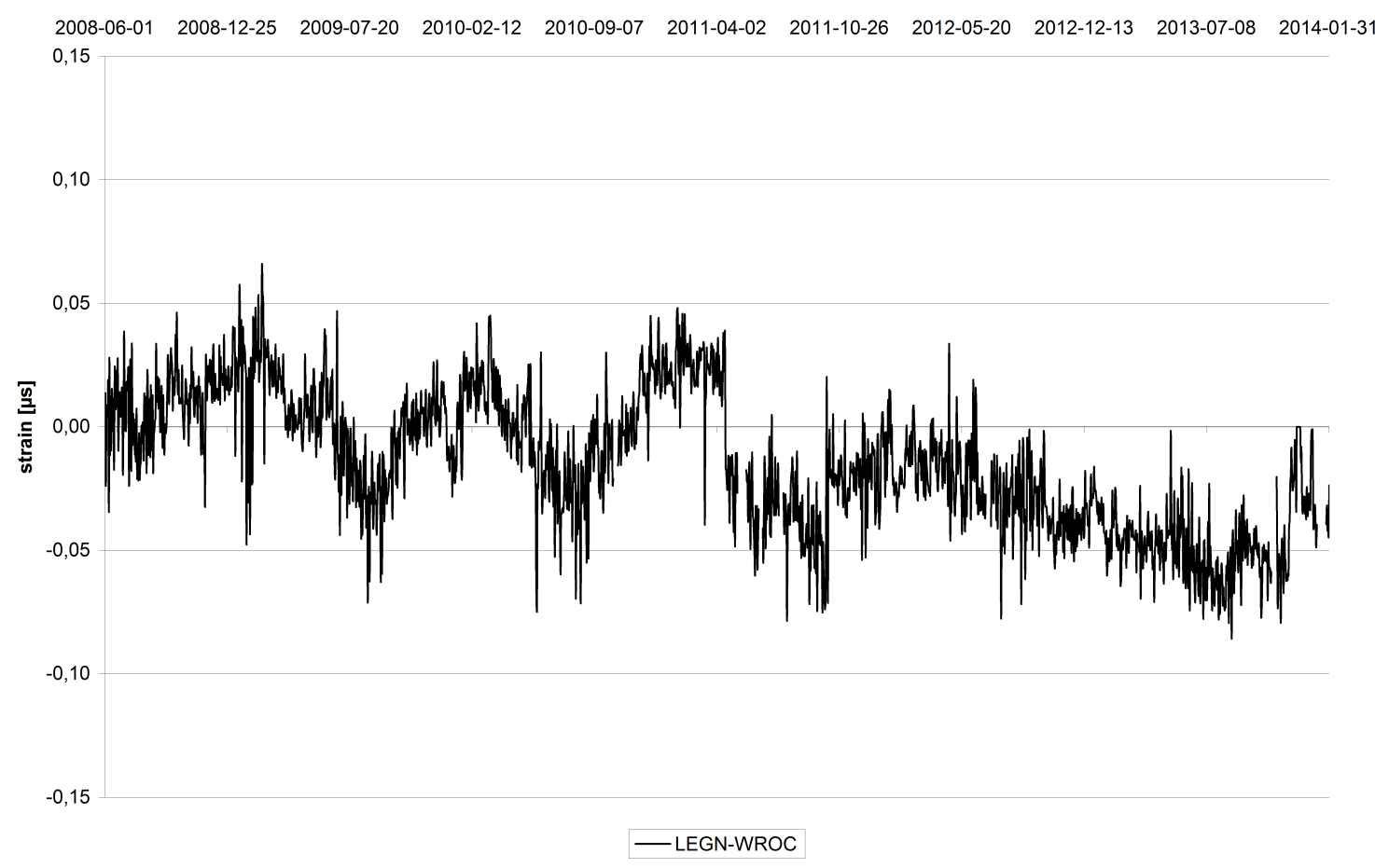

Figure 8. Temporal variation of apparent strain evaluated for the base LEGN-WROC

to examine this specific temporal distribution of the apparent strain. To identify a pattern comprising a cycle and an amplitude in the first step sine-wave fitting was applied. However, some regularities in the distribution are noticeable, numerical analysis provided ambiguous results (Fig. 9). Approximation by sine wave function provided that although amplitude is quite constant, cycle period is varying.

Presuming that observable oscillation is a seasonal effect (caused by various factors, usually weather or hydrological conditions), it is hard to understand that this effect doesn't occur in variations of apparent strain evaluated for the other base lines (GLOG-ZARY, GLOG-LESZN, GLOG-WROC). Only the distribution of the LEGN-WROC slightly remains oscillations observed in LEGN-GLOG and seasonal like oscillations occurred only between June 2008 and April 2011. In the base line, WLBRLEGN cycle seems to last about 2 years. So, LEGN-GLOG base line located in the central part of the examined area show a pattern of apparent strain variations suggesting certain seasonality but it doesn't occur in other combination of the stations. What's more, the distribution of the GLOG-WROC is very unwavering and the range of the variations is very small and this distance can be considered as constant; hence, deformation of the base line doesn't occur. So, the only clear oscillations of apparent strain are demonstrated by the LEGN-GLOG base. As it was mentioned, the alignment by sine function exist only in relatively narrow range of the data. The process looks as non-stationary and variations of the apparent strain should be considered as multimodal distributions with interlaced negative and positive peaks, although there are several peaks of the same height. Therefore, the next is to describe the peaks; hence, multi-peak Gaussian fitting was used. Each peak was estimated according to the following formula:

$$
y=y_{0}+\frac{A}{\sigma \sqrt{\frac{\pi}{2}}} e^{-\frac{2\left(X-X_{0}\right)^{2}}{\sigma^{2}}}
$$

where:

$y_{0}$ - baseline offset,
$A$ - total area under the curve from the baseline,

$X_{0}$ - centre of the peak,

$\sigma-$ the standard deviation, approximately 0.849 the width of the peak at half height.

This model describes a bell-shaped curve like the normal (Gaussian) probability distribution function. The centre represents the "mean". Fitting procedure is applied separately for negative and positive peaks. Fig. 10 presents a modelled distribution of apparent strain by the Gaussian function with positive and negative peaks outlining the interlaced compressions and relative extensions. Applied model provided a good statistical fit to the data and the computational results show a significant dispersion of the estimated parameters as $A$ or $\sigma$ that were determined for each peak. Tab. 1 shows the results: parameters of the model are listed according to peaks fitting maxima and minima of the distribution and the values of standard error on parameter value proved good fitting and mentioned remarks of changeability of the distribution. So, the appropriate values of amplitude or phase length evaluated from the presented parameters significantly varying and difference between the estimated values of particular peaks is sometimes more than three times. What's more, the results of statistical analysis provide small values of errors of estimated parameters. For example, errors amounted to values, which are less one or two orders as it is in the case of $X_{\mathrm{C}}$. As it is presented in Fig. 10, the positive and negative peaks outline the stress variation in time and very small value trend is noticeable - in the main compressions slightly increase in time. Interlaced negative and positive peaks demonstrated just increases of compressions and decreases of compressions, which can be regarded as relative extensions.

So, the examined apparent strain rates of the LEGN-GLOG base line should be considered as distribution having a remarkable repeatability of extrema in varying compressions. These results raise a question of whether varying in time values of compressions pertain to tectonic actions or they result in mining seismicity in the area. Both the issues can be related: observed compressions is a result of tectonic activity and tectonic 


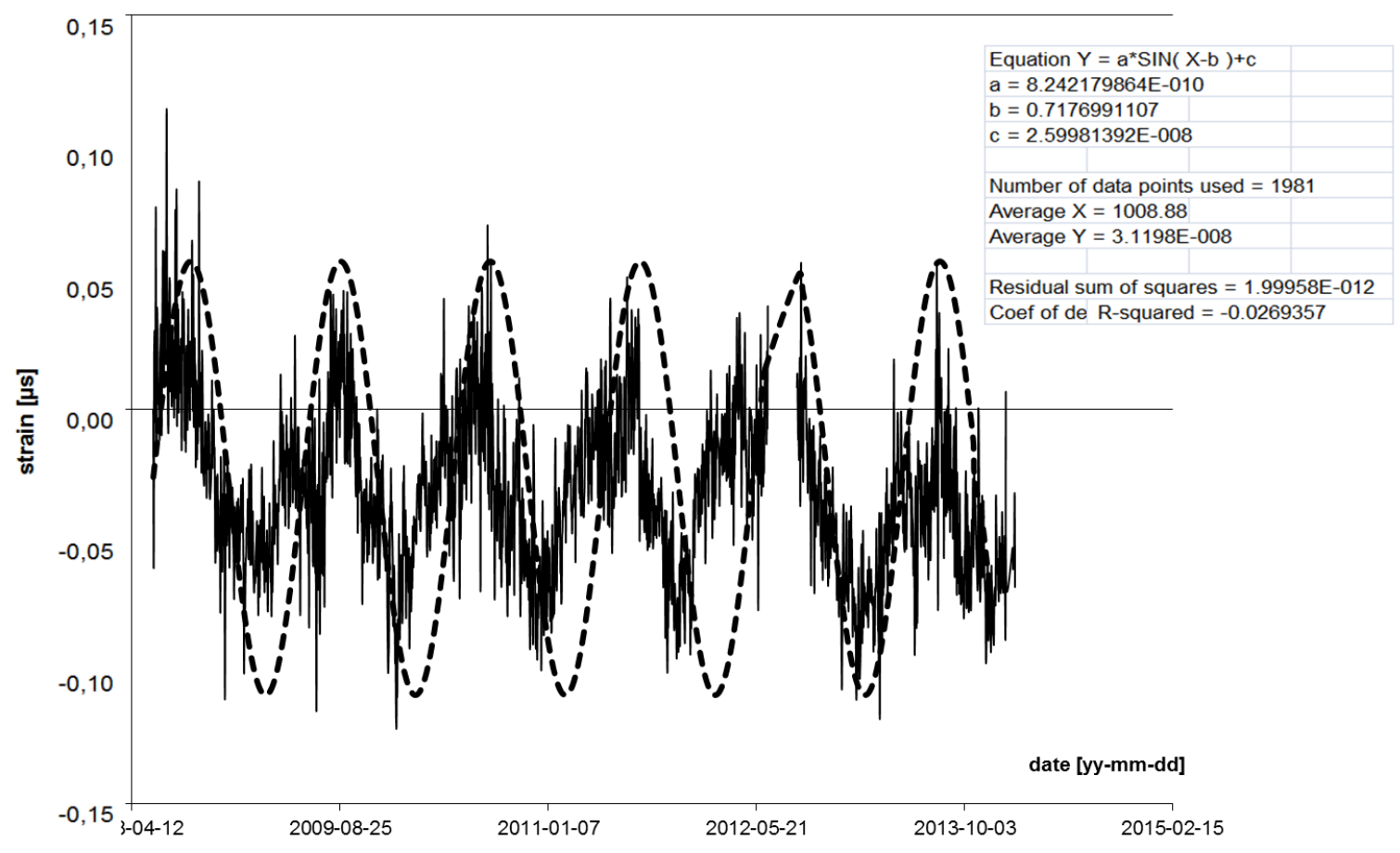

Figure 9. Approximation of LEGN-GLOG apparent strain variation by sine function (dashed line)

stress generating a response in the strongest mining tremors. To perceive tectonic stress effects influencing the temporal distribution of the apparent strain and impact in mining seismicity in LGCD, pulses of compression increase should be compared with the occurrence of large seismic events in time. Hence, the mentioned remarks concluded from the plot were validated in the next step analysis. Figures 11-12 demonstrate remarkable regularity: frequency distribution of large seismic events in LGCD $\left(M_{\mathrm{L}}>4\right)$ in time intervals (referenced to approximated $X_{\mathrm{C}}$ ) and evaluated for positive (relative extensions) and negative peaks (compressions) are scattered mostly in periods when compression increases. This remark is more obvious when very large events are analysed $\left(M_{L}>4.3\right)$ : frequency distributions presented in Fig. 13 shows how the occurrence of the events are "shifted away" from $X_{\mathrm{C}}$, which is a moment of minimal compressions and they are concentrated in period of increasing values of compressions (Fig. 14). The distributions presented on the mentioned figures are referenced to time intervals with respect to minimal or maximal values occurring in $X_{\mathrm{C}}$ moment of time. A form of time expressed in days is not very relevant due to inadequate parameters describing peaks. So, it is much better to involve $\sigma$ as a parameter depicting time and geometry of peak, especially its extreme value.

So, the data was processed to be presented in statistical form with the application of parameters describing the peaks $\left(X_{C}\right.$ and $\left.\sigma\right)$. The moment of seismic events were compiled, where the occurrence of centre of the peak $X_{c}$, which is a moment of time, when the minimal and maximal compression occurred. And time interval is related to $X_{\mathrm{C}}$ and expressed in the mean of $\sigma$. Fig. 15 presents a model of combined negative and positive peaks, which are described by the parameters of average values. This modelled performance of negative and positive peaks approximates temporal distribution of apparent strain of the LEGN-GLOG base as a function of $\sigma$ as velocity of the apparent strain rates variations. Occurrence of seismic events with magnitude $M_{\mathrm{L}}>4.0$ (small stars) and those with magnitude over 4.3 (big stars) concentrate in distinctive periods: $t_{\mathrm{s}}$ - period of maximal values of apparent strain rates, $t_{\mathrm{vs}}$ - period of maximal values of apparent strain rates velocities. However, the largest events $\left(M_{\mathrm{L}}\right.$ over 4.3$)$ did not occur in the period of significant relative extensions (in the range from $-0.6 \sigma$ to $0.6 \sigma$ ), but they concentrated just before the moments of extreme values of compressions.

On the basis of the remarks mentioned above, it can be stated that the increase of compressions makes the probability of occurrence of these events higher. Noticeable is their concentration, 50-100 days before the moment of maximal value of compressions. In the form of Gaussian function approximating distribution of tensions, this period of time equals 0.3$0.4 \sigma$, that can be considered as a moment of appearance of their major values. In fact, that's a moment of time when the increase of the tension is the highest. A concentration of the seismic events in periods of compression increase was observed. 28 seismic events with magnitude $M_{\mathrm{L}}>4.0$ were recorded and analysed between 2008-2014 in the area and just several of these occurred in the period of minimal compressions and the number of the events increases according to increase of the compression. This relation is more noticeable in the case of very high mining tremors with magnitude 4.3 or more $\left(M_{\mathrm{L}}>4.3\right)$. Ten events were observed within the analysed period and 9 occurred in the period on increase of compressions within $-0.7 \sigma$ and $X_{C}$.

Temporal pattern of the apparent strain of the analysed LEGN-GLOG baseline with unambiguous oscillations is surprising, considering much more disturbed temporal distribution of $\mathrm{N}$ and E components of particular station as LEGN (Fig. 3). So, the question arises if the data is influenced by artificial effect resulting from the applied technique or seasonal effects.

Seasonal signals are observed in the geodetic position time series of Global Navigation Satellite System (GNSS) stations at a global or a regional scale. Identifying and extracting nontectonic seasonal signals from geodetic measurements is nowadays a problem widely discussed by researches (Blewitt et al., 2001; Dong et al., 2002; van Dam et al., 2001). However, the problem is usually analysed in the aspect of height variation and in tectonically active areas in the regional scale, it should 

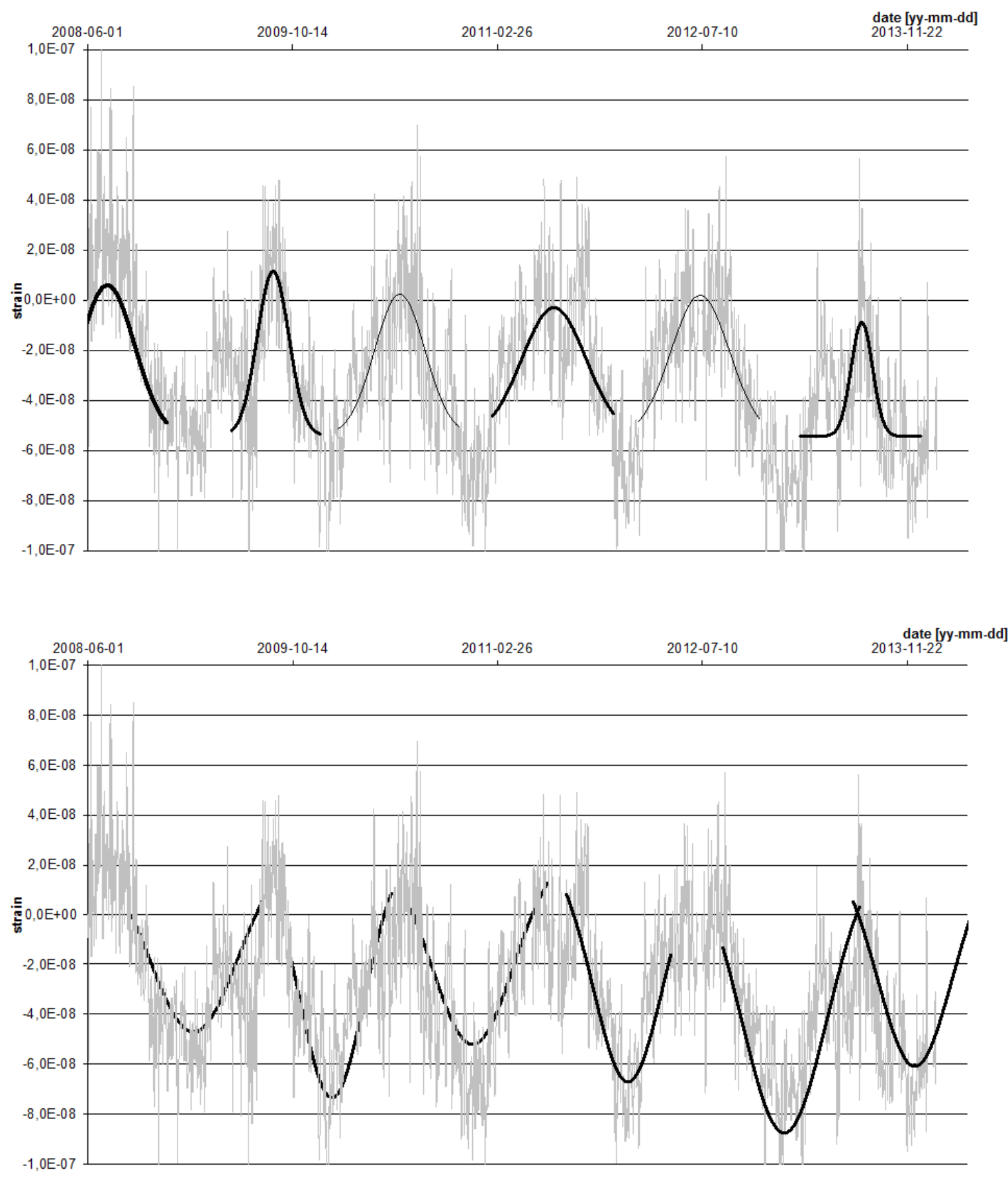

Figure 10. Approximation of apparent strain variation by multi-peak Gaussian for positive and negative peaks separately 


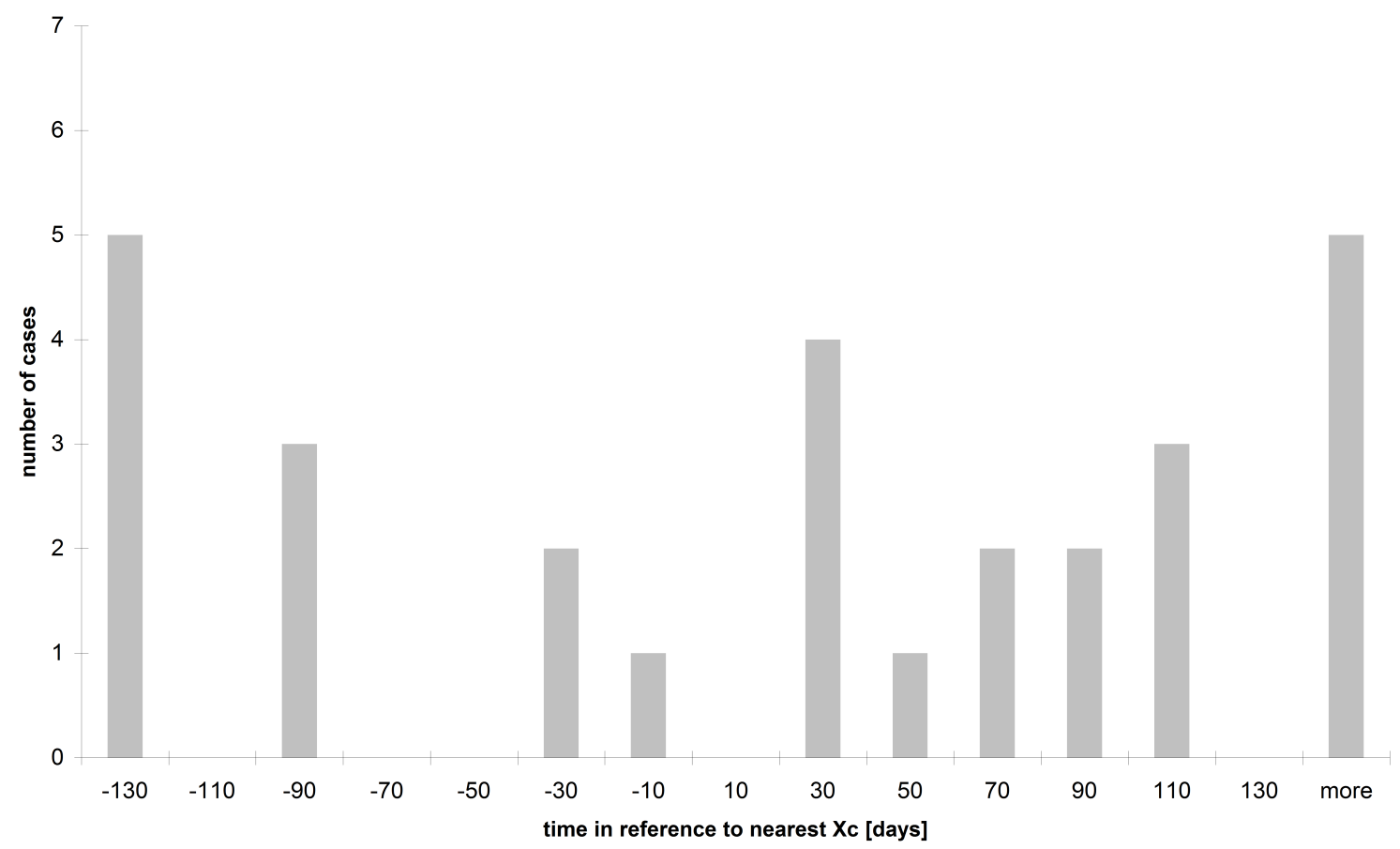

Figure 11. Frequency distribution of large seismic events in LGCD $\left(M_{\mathrm{L}}>4\right)$ in time intervals referenced to approximated $\mathrm{X}_{\mathrm{c}}$ evaluated for positive peaks

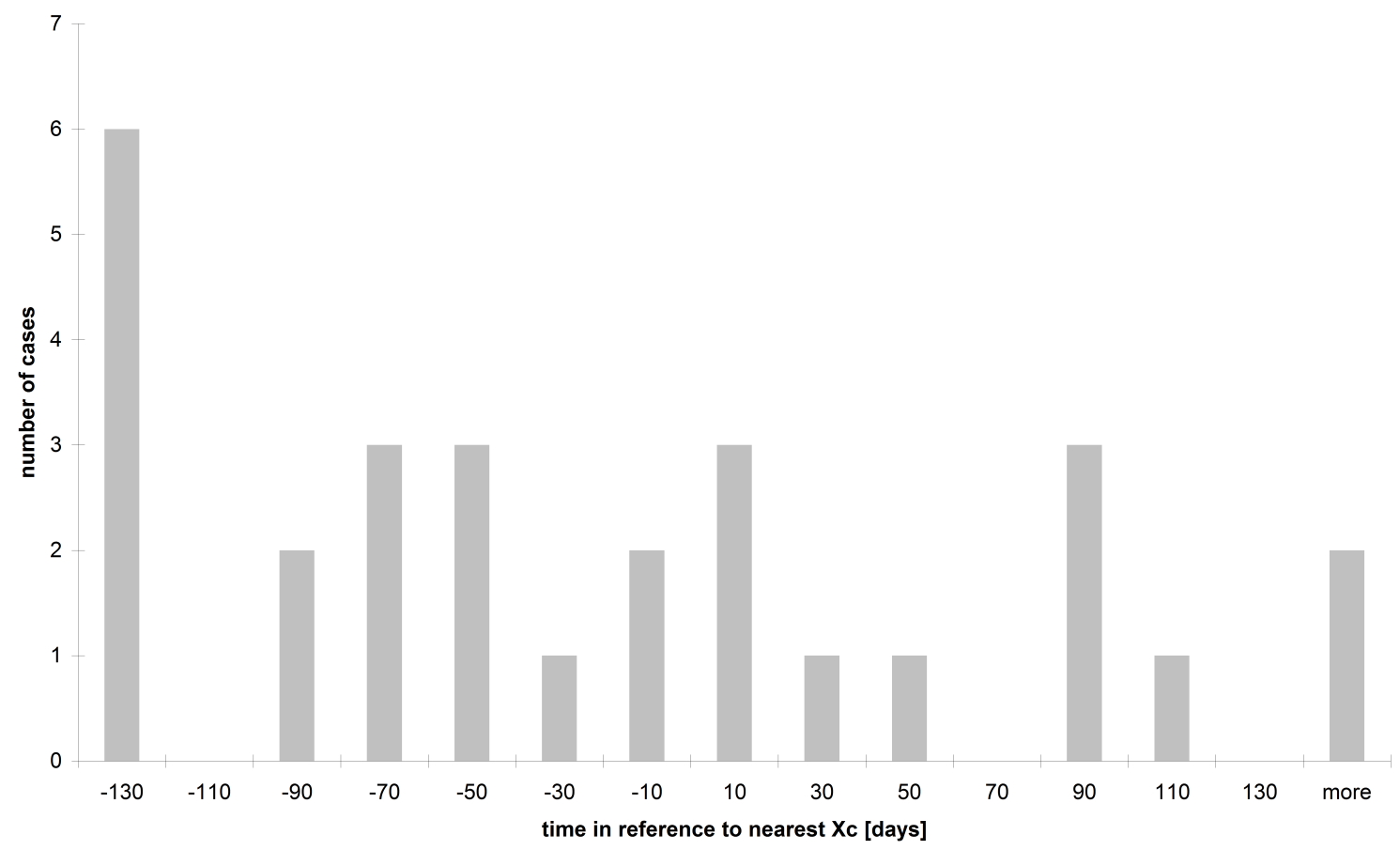

Figure 12. Frequency distribution of large seismic events in $\operatorname{LGCD}\left(M_{\mathrm{L}}>4\right)$ in time intervals referenced to approximated $\mathrm{X}_{\mathrm{c}}$ evaluated for negative peaks 


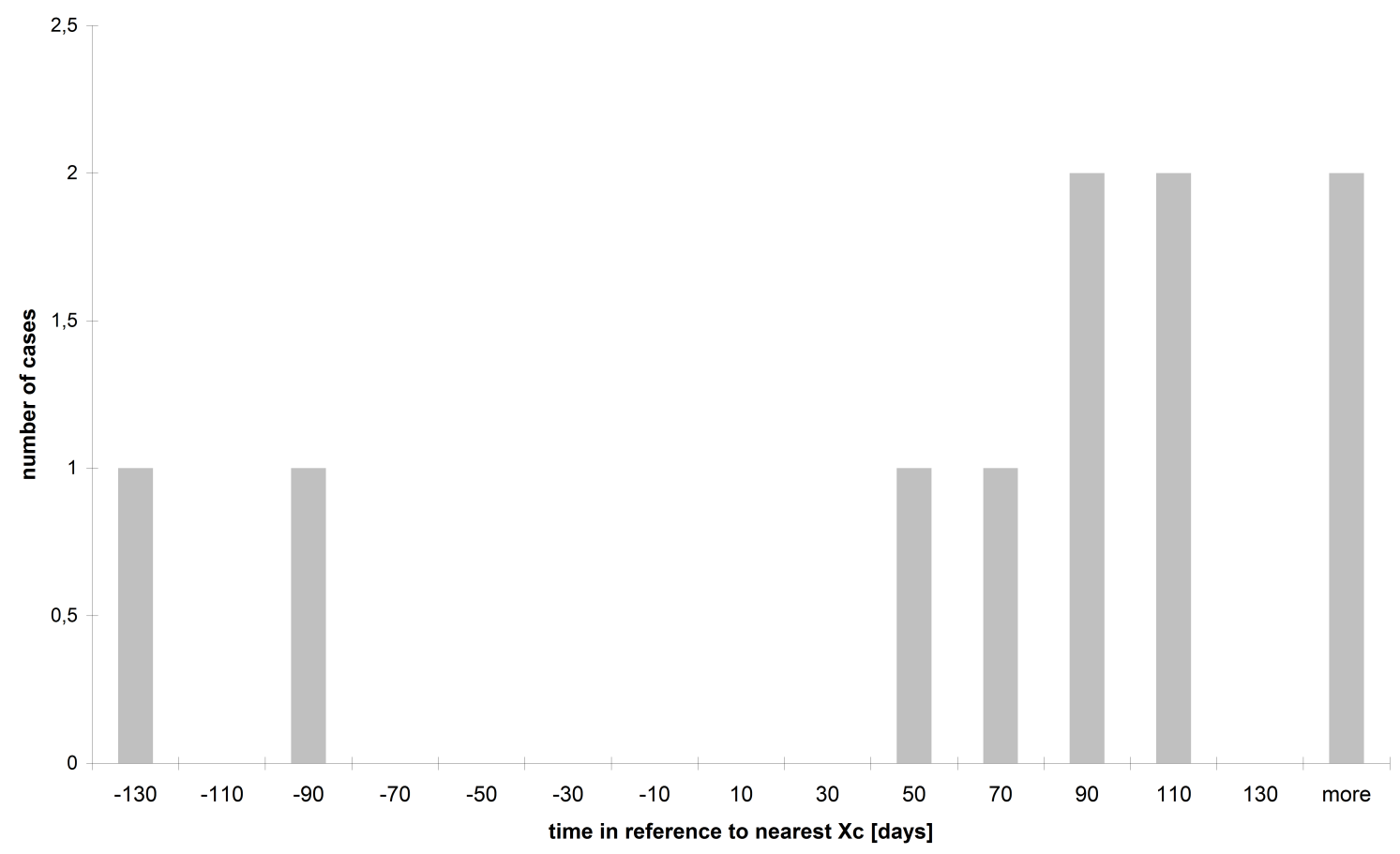

Figure 13. Frequency distribution of very large seismic events in LGCD $M_{\mathrm{L}}>4.3$ ) in time intervals referenced to approximated $\mathrm{X}_{\mathrm{c}}$ evaluated for positive peaks

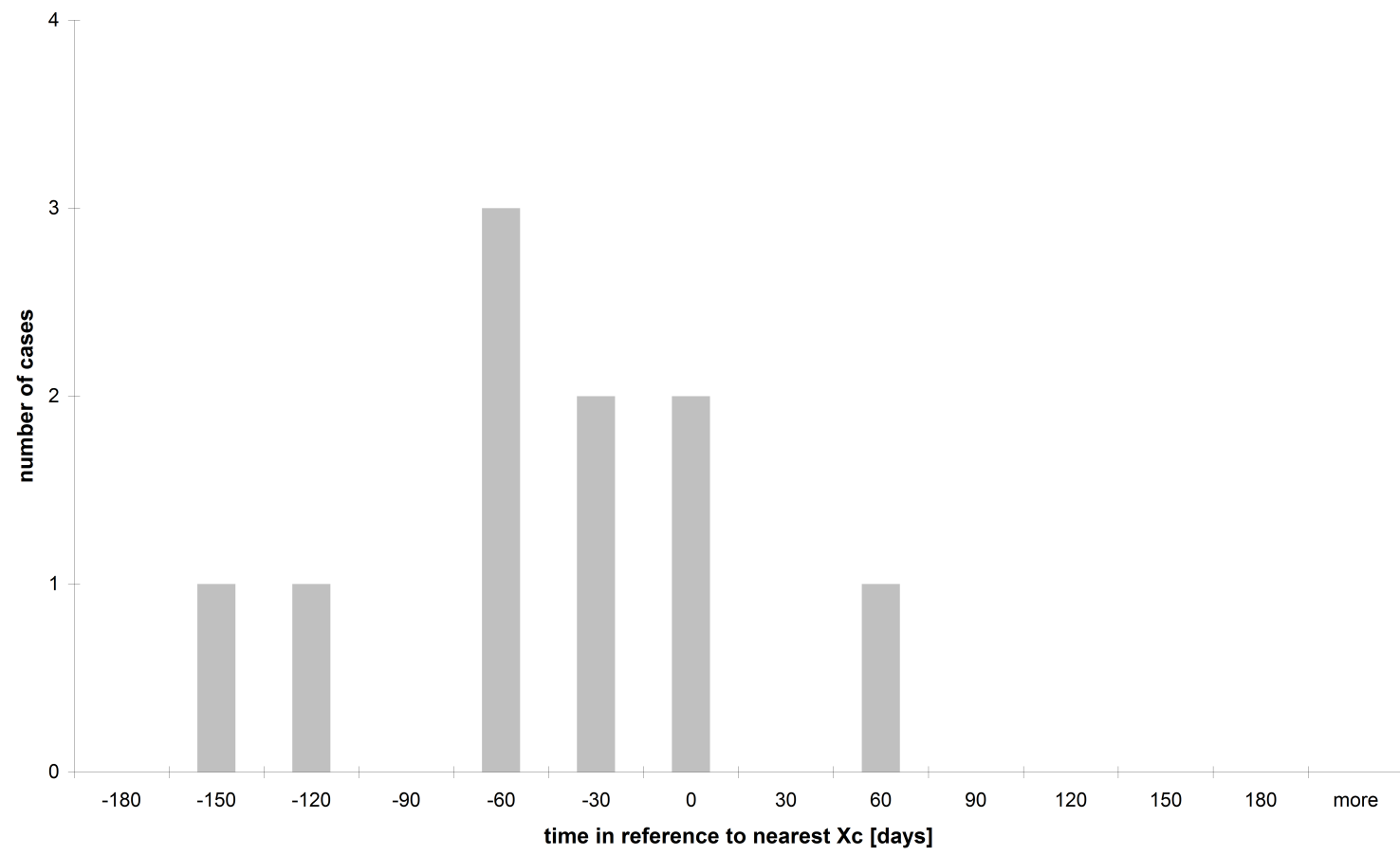

Figure 14. Frequency distribution of very large seismic events in $\operatorname{LGCD}\left(M_{\mathrm{L}}>4.3\right)$ in time intervals referenced to approximated $X_{\mathrm{C}}$ evaluated for negative peaks 
Table 1. Evaluated parameters of Gaussian peak and the values are expressed in $\mathrm{mm} / \mathrm{m}$ for positive and negative peaks

\begin{tabular}{|c|c|c|c|c|c|c|}
\hline \multirow[b]{2}{*}{ Parameter } & \multicolumn{3}{|c|}{ Positive peaks } & \multicolumn{3}{|c|}{ Negative peaks } \\
\hline & $\begin{array}{l}\text { Parameter of } \\
\text { successive } \\
\text { peak }\end{array}$ & $\begin{array}{c}\text { Value of } \\
\text { parameter }\end{array}$ & $\begin{array}{l}\text { Standard } \\
\text { error on } \\
\text { parameter } \\
\text { value }[ \pm]\end{array}$ & $\begin{array}{l}\text { Parameter of } \\
\text { successive } \\
\text { peak }\end{array}$ & $\begin{array}{l}\text { Value of } \\
\text { parameter }\end{array}$ & $\begin{array}{l}\text { Standard } \\
\text { error on } \\
\text { parameter } \\
\text { value }[ \pm]\end{array}$ \\
\hline \multirow{6}{*}{ 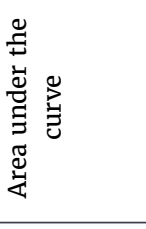 } & $A_{1}$ & $1.00 \mathrm{E}-05$ & $8.7 \mathrm{E}-07$ & $A_{1}$ & $-2.00 E-05$ & $2.5 \mathrm{E}-06$ \\
\hline & $A_{2}$ & $6.32 \mathrm{E}-06$ & $3.8 \mathrm{E}-07$ & $A_{2}$ & $-2.00 \mathrm{E}-05$ & $1.3 \mathrm{E}-06$ \\
\hline & $A_{3}$ & $8.69 \mathrm{E}-06$ & $5.2 \mathrm{E}-07$ & $A_{3}$ & $-2.00 \mathrm{E}-05$ & $2.2 \mathrm{E}-06$ \\
\hline & $A_{4}$ & $1.00 \mathrm{E}-05$ & $6.2 \mathrm{E}-07$ & $A_{4}$ & $-2.00 E-05$ & $1.7 \mathrm{E}-06$ \\
\hline & $A_{5}$ & $1.00 \mathrm{E}-05$ & $5.7 \mathrm{E}-07$ & $A_{5}$ & $-3.00 E-05$ & $2.3 \mathrm{E}-06$ \\
\hline & $A_{6}$ & $2.94 \mathrm{E}-06$ & $3.0 \mathrm{E}-07$ & $A_{6}$ & $-2.00 \mathrm{E}-05$ & $2.4 \mathrm{E}-06$ \\
\hline \multirow{6}{*}{ 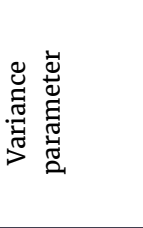 } & $\sigma_{1}$ & 132.66 & 8.8 & $\sigma_{1}$ & 214.57 & 8.8 \\
\hline & $\sigma_{2}$ & 76.45 & 4.7 & $\sigma_{2}$ & 158.53 & 4.7 \\
\hline & $\sigma_{3}$ & 122.52 & 7.3 & $\sigma_{3}$ & 200.56 & 7.3 \\
\hline & $\sigma_{4}$ & 156.23 & 8.1 & $\sigma_{4}$ & 168.70 & 8.1 \\
\hline & $\sigma_{5}$ & 142.20 & 7.6 & $\sigma_{5}$ & 208.56 & 7.6 \\
\hline & $\sigma_{6}$ & 51.88 & 5.5 & $\sigma_{6}$ & 180.74 & 5.5 \\
\hline \multirow{6}{*}{ 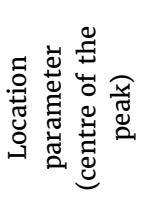 } & $X c_{1}$ & 39649.70 & 4.2 & $X c_{1}$ & 39857.79 & 3.4 \\
\hline & $X c_{2}$ & 40053.37 & 2.2 & $X c_{2}$ & 40196.02 & 2.8 \\
\hline & $X c_{3}$ & 40362.52 & 3.3 & $X c_{3}$ & 40538.98 & 2.9 \\
\hline & $X c_{4}$ & 40738.03 & 3.7 & $X c_{4}$ & 40917.27 & 2.7 \\
\hline & $X c_{5}$ & 41093.74 & 3.4 & $X c_{5}$ & 41300.57 & 3.8 \\
\hline & $X c_{6}$ & 41489.72 & 2.6 & $X c_{6}$ & 41619.09 & 7.2 \\
\hline 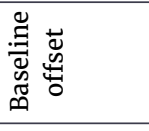 & $y_{0}$ & $-5.439 \mathrm{E}-08$ & $1.0542 \mathrm{E}-09$ & $y_{0}$ & $2.74 \mathrm{E}-08$ & $4.987 \mathrm{E}-09$ \\
\hline \multirow{6}{*}{ 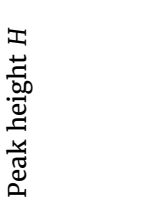 } & $H_{1}$ & $8.4 \mathrm{E}-08$ & $3.8 \mathrm{E}-07$ & $H_{1}$ & $2.7 \mathrm{E}-09$ & $2.5 \mathrm{E}-06$ \\
\hline & $\mathrm{H}_{2}$ & $8.7 \mathrm{E}-08$ & $5.2 \mathrm{E}-07$ & $\mathrm{H}_{2}$ & $5.6 \mathrm{E}-09$ & $1.3 \mathrm{E}-06$ \\
\hline & $\mathrm{H}_{3}$ & $8.3 E-08$ & $6.2 \mathrm{E}-07$ & $\mathrm{H}_{3}$ & $8.8 \mathrm{E}-10$ & $2.2 \mathrm{E}-06$ \\
\hline & $\mathrm{H}_{4}$ & $8.0 \mathrm{E}-08$ & $5.7 \mathrm{E}-07$ & $\mathrm{H}_{4}$ & $-1.9 \mathrm{E}-09$ & $1.7 \mathrm{E}-06$ \\
\hline & $\mathrm{H}_{5}$ & $8.2 \mathrm{E}-08$ & $3.0 \mathrm{E}-07$ & $\mathrm{H}_{5}$ & $6.5 \mathrm{E}-10$ & $2.3 \mathrm{E}-06$ \\
\hline & $\mathrm{H}_{6}$ & $7.7 \mathrm{E}-08$ & $8.8 \mathrm{E}+00$ & $\mathrm{H}_{6}$ & $-4.8 \mathrm{E}-09$ & $2.4 \mathrm{E}-06$ \\
\hline
\end{tabular}

be considered here due to seismicity, which in many areas demonstrate seasonality. So, the most recent studies are devoted to the problem of seismic events' variation in California and Nepal in relation to factors such as snow and surface hydrology loading as to oscillation of geodetic displacements (Bollinger et al., 2007; Bettinelli et al., 2006; Johnson et al., 2017). Relation between hydrological loading cycles and the resulting stress changes on fault planes of small earthquakes in California is reported by Johnson et al. (2017). According to the authors, the seasonal loading analysis reveals earthquakes occurring more frequently during stress conditions that favour earthquake rupture in northern California. They conclude that and seismicity rates are modestly modulated by natural hydrological loading cycles in that area. The general conclusion is that tectonic and hydrological effects could be combined and a contribution of particular factor in varying apparent strain rates is another problem to be considered. So, the author concentrates on statistical significance of apparent strain rates and tremors occurrence in small regional scale of LGCD area.

Artificial effects can influence the data, but these clear oscillations are revealed only in the LEGN-GLOG baseline and mostly in the $\mathrm{N}$ component of the stations' positions. What is more, they obtained results of apparent strain performance corresponding to those presented in the work by Araszkiewicz et al. (2016). This fundamental work in subject of stress field in Poland presents apparent strain vectors evaluated for the studied area show similar rates and orientations, which follow from the study presented here.

However, the presented reasoning doesn't provide direct evidence of tectonic activity of the area and the toil of that activity in high energy seismic events in the area of LGCD, evaluated performance of apparent strain rates variations of the LEGN and GLOG stations and its relations with occurrence with the events is clear and a tectonic mechanism seems to be obvious and justified.

\section{Conclusions}

Examined displacements and the surface apparent strain derived from GPS/GNSS measurements of ASG-EUPOS stations of the area of LGCD are presented in this study. Temporal distributions of apparent strain of the bases GLOG-ZARY, GLOGLESZN, GLOG-WROC and LEGN-GLOG were analysed. The most significant values as their distinctive variation in time were observed in the LEGN-GLOG base. So the performance of compressions of this base was modelled and their distribution was approximated by multi peak Gaussian. So, the parameters of the model were evaluated and its temporal characteristic was referenced to moments of high energy seismic event occurred in the area. The significant relations were observed. Periods involving high value of compressions of the LEGN-GLOG base are favoured in distribution of large seismic event: and the occurrence of the events seem to be predicated on the increase of the compressions (high value of velocity of apparent strain rates). These relations are much more clear for very large events $\left(M_{L}>4.3\right)$. However, the occurrence of this small a number of the cases in a relatively long time period could be considered as accidental; a remarkable fact is that they never occurred when the compressions were small. 


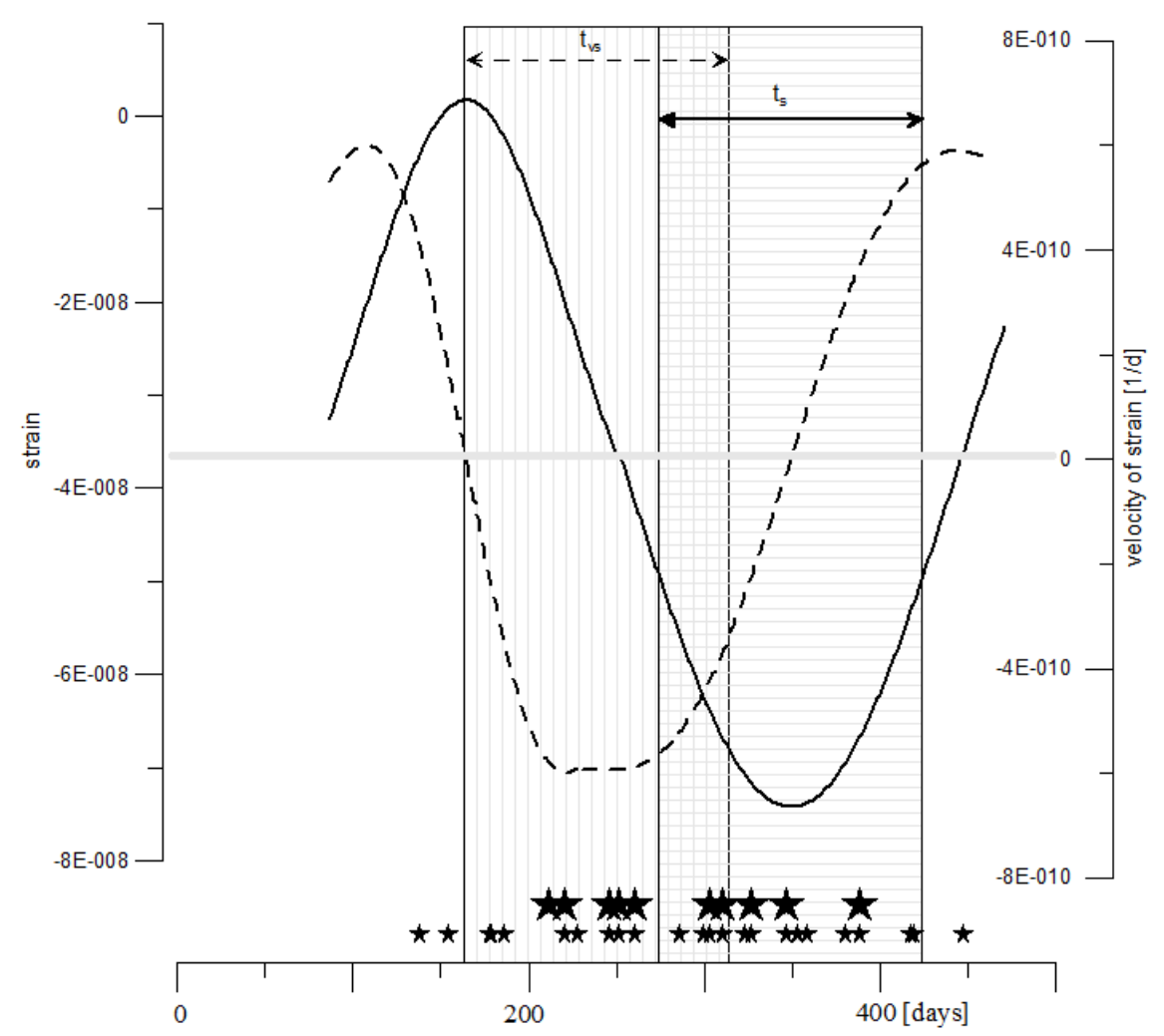

Figure 15. Modelled negative and positive peaks approximating apparent strain of the LEGN-GLOG base and velocity of the apparent strain rates' variations. Small stars: occurrence of seismic events with magnitude $M_{\mathrm{L}}>4.0$ and big ones with magnitude over 4.3. Distinctive periods: $t_{\mathrm{s}}$ - period of maximal values of apparent strain rates, $t_{\mathrm{vs}}$ - period of maximal values of strain rates velocities.

Considering the regional subsidence or manifestation of tectonic activity of the area mentioned earlier, it can be presumed that vertical displacement could involve horizontal displacements in fault zones, which is a probable mechanism producing tectonic stress. The LEGN and GLOG stations are located on different geological units and they are separated by the Middle Odra Northern Fault. That could be a cause of the observed distance changes, which are significantly varying in time, which makes this base unique in the group of ASG-EUPOS stations surrounding the area of LGCD. Presuming tectonic stress as a cause of observed compressions and their relations with the occurrence of the high energy seismic events, it can be stated that during the events, accumulated stress is released and the stress has a tectonic component as well.

\section{Acknowledgements}

The study presented here was carried out within the statutory research project No. 11.11.150.195 at AGH University of Science and Technology, Faculty of Mining Surveying and Environmental Engineering, Department of Mining Areas Protection, Geoinformatics and Mining Surveying in Krakow. The work was supported by the Polish Ministry of Science and Higher Education and its grants for Scientific Research. Special thanks to the Authority of ASG-EUPOS for data and Prof. Janusz Bogusz for his professional and constructive support.

\section{References}

Araszkiewicz, A., Bogusz, J., Figurski, M., Kroszczyński, K., and Szafranek, K. (2009). Report from 30.06.2009 dealing with precise elaboration of observational data from permanent stations of ASG-EUPOS system. Technical report, The Military Technical Academy. Access: http://www .asgeupos.pl/webpg/graph/img/_syst_tests/ 20090630_WAT-CGS_RaportASG-EUPOS.pdf.

Araszkiewicz, A., Figurski, M., and Jarosiński, M. (2016). Erroneous GNSS strain rate patterns and their application to investigate the tectonic credibility of GNSS velocities. Acta Geophysica, 64(5):1412-1429, doi:10.1515/acgeo-2016-0057.

Bettinelli, P., Avouac, J.-P., Flouzat, M., Jouanne, F., Bollinger, L., Willis, P., and Chitrakar, G. R. (2006). Plate motion of India and interseismic strain in the Nepal Himalaya from GPS and DORIS measurements. Journal of Geodesy, 80(8-11):567589, doi:10.1007/s00190-006-0030-3.

Blewitt, G., Lavallée, D., Clarke, P., and Nurutdinov, K. (2001). A new global mode of Earth deformation: Seasonal cycle detected. Science, 294(5550):2342-2345, doi:10.1126/science.1065328.

Bogusz, J., Figurski, M., Kontny, B., and Grzempowski, P. (2012). Horizontal velocity field derived from EPN and ASGEUPOS satellite data on the example of south-western part of Poland. Acta Geodynamica et Geomaterialia, 9:349-357.

Bogusz, J., Kłos, A., Grzempowski, P., and Kontny, B. (2014). Modelling the velocity field in a regular grid in the area of Poland on the basis of the velocities of European permanent stations. Pure and Applied Geophysics, 171(6):809-833, doi:10.1007/s00024-013-0645-2.

Bollinger, L., Perrier, F., Avouac, J.-P., Sapkota, S., Gautam, U., and Tiwari, D. (2007). Seasonal modulation of seismicity in the Himalaya of Nepal. Geophysical Research Letters, 34(8), doi:10.1029/2006GL029192.

Bosy, J., Graszka, W., and Leończyk, M. (2007). ASG-EUPOS - a multifunctional precise satellite positioning system in Poland. TransNav, International Journal on Marine Navigation and Safety od Sea Transportation, 1(4):371-374. 
Brzeziński, A., Jóźwik, M., Kaczorowski, M., Kalarus, M., Kasza, D., Kosek, W., Nastula, J., Szczerbowski, Z., Wińska, M., Wronowski, R., Zdunek, R., and Zieliński, J. B. (2016). Geodynamic research at the Department of Planetary Geodesy, SRC PAS. Reports on Geodesy and Geoinformatics, 100(1):131-147, doi:10.1515/rgg-2016-0011.

Cacon, S., Bosy, J., and Kontny, B. (2004). Recent tectonic activity in the Eastern Sudetes and on the Fore-Sudetic Block on the basis of 1993-2003 investigations. Reports on Geodesy, 2(69):197-211.

Crowell, B. W., Bock, Y., and Melgar, D. (2012). Real-time inversion of GPS data for finite fault modeling and rapid hazard assessment. Geophysical Research Letters, 39(9):L09305, doi:10.1029/2012GL051318.

Dadlez, R., Marek, S., and Pokorski, J. (2000). Geological map of Poland without Cainozoic deposits. Państwowy Instytut Geologiczny.

Dong, D., Fang, P., Bock, Y., Cheng, M., and Miyazaki, S. (2002). Anatomy of apparent seasonal variations from GPSderived site position time series. Journal of Geophysical Research: Solid Earth, 107(B4), doi:10.1029/2001JB000573.

Feigl, K. L. (2002). Estimating earthquake source parameters from geodetic measurements. In Lee, W. H. K., Kanamori, H., Jennings, P. C., and Kisslinger, C., editors, International Handbook of Earthquake and Engineering Seismology, volume 81A, pages 607-620. Elsevier, Amsterdam.

Figurski, M., Szafranek, K., Bogusz, J., and Kamiński, P. (2010). Investigation on stability of mountainous EUPOS sites' coordinates. Acta Geodynamica et Geomaterialia, 7(3):263-274.

Grzempowski, P., Badura, J., Cacoń, S., Kapłon, J., Rohm, W., and Przybylski, B. (2012). Geodynamics of south-eastern part of the Central European subsidence zone. Acta Geodynamica et Geomaterialia, 9(3):167.

Grzempowski, P., Badura, J., Cacoń, S., and Przybylski, B. (2009). Recent vertical movements in the Wroclaw section of the middle Odra fault zone. Acta Geodynamica et Geomaterialia, 6(3):339-349.

Jarosiński, M. (2010). Recent tectonic stress field investigations in Poland: a state of the art. Geological Quarterly, 50(3):303-321.

Johnson, C. W., Fu, Y., and Bürgmann, R. (2017). Seasonal water storage, stress modulation, and California seismicity. Science, 356(6343):1161-1164, doi:10.1126/science.aak9547.

Kaczorowski, M. and Wojewoda, J. (2011). Neotectonic activity interpreted from a long water-tube tiltmeter record at the SRC Geodynamic Laboratory in Książ, Central Sudetes, SW Poland. Acta Geodyn. Geomater, 8(3):249-261.

Klos, A., Bogusz, J., Figurski, M., and Kosek, W. (2015). Irregular variations in GPS time series by probability and noise analysis. Survey review, 47(342):163-173, doi:10.1179/1752270614Y.0000000133.

Kontny, B. (2004). Is the Sudetic Marginal Fault still active? Results of the GPS monitoring 1996-2002. Acta Geodynamica et Geomaterialia, 1(3):35-39.

Kontny, B. and Bogusz, J. (2012). Models of vertical movements of the Earth crust surface in the area of Poland derived from leveling and GNSS data. Acta Geodynamica et Geomaterialia, 9(3):331-337.

Košt'ák, B., Mrlina, J., Stemberk, J., and Chán, B. (2011). Tectonic movements monitored in the Bohemian Massif. Journal of Geodynamics, 52(1):34-44, doi:10.1016/j.jog.2010.11.007.

Lengliné, O., Elkhoury, J. E., Daniel, G., Schmittbuhl, J., Toussaint, R., Ampuero, J.-P., and Bouchon, M. (2012). Interplay of seismic and aseismic deformations during earthquake swarms: An experimental approach. Earth and Planetary Science Letters, 331-332:215-223, doi:10.1016/j.epsl.2012.03.022.
Lohman, R. B. and McGuire, J. J. (2007). Earthquake swarms driven by aseismic creep in the Salton Trough, California. Journal of Geophysical Research: Solid Earth, 112(B4):B04405, doi:10.1029/2006JB004596.

Majcherczyk, T. and Niedbalski, Z. (2017). The impact of multiple seam mining exploitations on seismic activity and state of stress. Studia Geotechnica et Mechanica, 39(1):53-62, doi:10.1515/sgem-2017-0005.

McCaffrey, R. (2005). Block kinematics of the Pacific-North America plate boundary in the southwestern United States from inversion of GPS, seismological, and geologic data. Journal of Geophysical Research: Solid Earth, 110(B7):B07401, doi:10.1029/2004JB003307.

Melgar, D., Bock, Y., and Crowell, B. W. (2012). Real-time centroid moment tensor determination for large earthquakes from local and regional displacement records. Geophysical Journal International, 188(2):703-718, doi:10.1111/j.1365246X.2011.05297.x.

Orlecka-Sikora, B., Papadimitriou, E. E., and Kwiatek, G. (2009). A study of the interaction among mining-induced seismic events in the Legnica-Głogów Copper District, Poland. Acta Geophysica, 57(2):413-434, doi:10.2478/s11600008-0085-z.

Pilecka, E. (2007). Statistical analysis of the relation between locations of high energy epicenter tremors and lineaments in areas of the Upper Silesian Basin. Gospodarka Surowcami Mineralnymi, 23(4):101-109.

Pilecka, E. (2008). An analysis of lineament directions on satellite images in context of the occurrence of an induced seismicity in the Legnica-Glogow Copper District (LGCD). Gospodarka Surowcami Mineralnymi, 24(2):135-146.

Popiołek, E., Ostrowski, J., Czaja, J., and Mazur, J. (2001). The impact of a strong mining tremor on the subsidence of the area surface in the Legnica-Glogow Copper Area. In The 1oth FIG International Symposium on Deformation Measurements, Orange, California USA, pages 77-80.

Schenk, V., Schenkova, Z., and Jechumtálová, Z. (2009). Geodynamic pattern of the West Bohemia region based on permanent GPS measurements. Studia Geophysica et Geodaetica, 53(3):329-341, doi:10.1007/s11200-009-0021-y.

Sokoła-Szewioła, V. (2011). Przebieg zaobserwowanych przemieszczeń pionowych terenu górniczego w czasookresie związanym z wystąpieniem wstrząsu indukowanego eksploatacją ścianową. Górnictwo i Geologia, 6(3):157-168.

Stemberk, J., Košt'ák, B., and Cacoń, S. (2010). A tectonic pressure pulse and increased geodynamic activity recorded from the long-term monitoring of faults in Europe. Tectonophysics, 487(1-4):1-12, doi:10.1016/j.tecto.2010.03.001.

Szczerbowski, Z. (2016). Investigation on reflection of tectonic pattern in ASG EUPOS data in the Sudetes and adjacent areas. Reports on Geodesy and Geoinformatics, 102(1):3251, doi:10.1515/rgg-2016-0026.

Szczerbowski, Z. and Jura, J. (2015). Mining induced seismic events and surface deformations monitored by GPS permanent stations. Acta Geodynamica et Geomaterialia, 12(3):237248, doi:10.13168/AGG.2015.0023.

Tong, X., Smith-Konter, B., and Sandwell, D. T. (2014). Is there a discrepancy between geological and geodetic slip rates along the San Andreas Fault System? Journal of Geophysical Research: Solid Earth, 119(3):2518-2538, doi:10.1002/2013JB010765.

van Dam, T., Wahr, J., Milly, P. C. D., Shmakin, A. B., Blewitt, G., Lavallée, D., and Larson, K. M. (2001). Crustal displacements due to continental water loading. Geophysical Research Letters, 28(4):651-654, doi:10.1029/2000GL012120.

Wanior, J. (1983). Method of prognosis of tremors or rock bursts on the base of results of geodetic measurements on the example of mining carried in the protection pillar of Bytom city. $\mathrm{PhD}$ thesis, 
UST AGH in Krakow.

Wdowinski, S., Bock, Y., Zhang, J., Fang, P., and Genrich, J. (1997). Southern California permanent GPS geodetic array: Spatial filtering of daily positions for estimating coseismic and postseismic displacements induced by the 1992 Landers earthquake. Journal of Geophysical Research: Solid Earth, 102(B8):18057-18070, doi:10.1029/97JB01378.
Wiejacz, P. and Gibowicz, S. J. (1997). Source mechanism determined by moment tensor inversion for seismic events at Rudna and Polkowice copper mines in Poland. Acta Geophysica Polonica, 45:291-302.

Zorychta, A. and Burtan, Z. (2012). Conditions of fault activation in the area of exploitation. Mining and Geoengineering, 36(3):509-519, doi:110.7494/mining.2012.36.3.509. 